FINAL REPORT

U.S. Department of Energy

\title{
SYNTHESIS AND CHARACTERIZATION OF TEMPLATED ION EXCHANGE RESINS FOR THE SELECTIVE COMPLEXATION OF ACTINIDE IONS
}

\author{
Principal Investigator: \\ George M. Murray \\ Johns Hopkins University Applied Physics Lab \\ 11100 Johns Hopkins Road \\ Laurel, Maryland 20723-6099 \\ 443-778-3882, murragm1@aplcomm.jhuapl.edu

\section{Collaborators:} \\ O. Manuel Uy \\ Johns Hopkins University Applied Physics Lab \\ 11100 Johns Hopkins Road \\ Laurel, Maryland 20723-6099 \\ 443-778-5334, uyom1@aplmsg.jhuapl.edu \\ Xiangfei Zeng, Sue Y. Bae, Anton Bzhelyanskiy \& Anael Kimaro \\ Department of Chemistry \& Biochemistry \\ University of Maryland, Baltimore County \\ Baltimore, MD 21250
}

Project Number: 59977

Grant Number: FG07-97ER14823

Grant Project Officers:

Richard Gordon

Ramonacita Masey

Project Duration: 9/15/97 to 3/14/01 


\section{Table of Contents}

Cover page $\quad$ i.

Table of Contents

I. Executive Summary 1

II. Research Objectives 4

III. Methods and Results $\quad 4$

IV. Relevance, Impact, and Technology Transfer 13

$\begin{array}{ll}\text { V. Project Productivity } & 14\end{array}$

$\begin{array}{ll}\text { VI. Personnel Supported } & 15\end{array}$

$\begin{array}{ll}\text { VII. Publications } & 15\end{array}$

$\begin{array}{lc}\text { VIII. Interactions } & 16\end{array}$

$\begin{array}{ll}\text { IX. Patents } & 16\end{array}$

$\begin{array}{ll}\text { X. Future Work } & 17\end{array}$

$\begin{array}{ll}\text { XI. Literature Cited } & 17\end{array}$

$\begin{array}{ll}\text { XII. Feedback } & 17\end{array}$

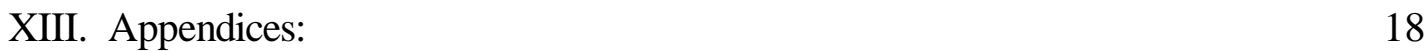




\section{Executive Summary}

The objective of this research was to develop polymeric extractants for the selective complexation of uranyl ions (and subsequently other actinyl and actinide ions) from aqueous solutions. Selectivity for a specific actinide ion is obtained by providing polymers with cavities lined with complexing ligands so arranged as to match the charge, coordination number, coordination geometry, and size of the actinide ion. These cavity-containing polymers are produced by using a specific actinide ion as a template around which monomeric complexing ligands are polymerized. The polymers have provided useful sequestering agents for removing actinide ions from wastes and the basis for a variety of analytical techniques for actinide determination.

This report describes the development of a variety of polymeric extractants for the selective complexation of uranyl ions from aqueous solutions. The polymers were produced by a process now known as molecular imprinting. Molecular imprinting is a process for making selective binding sites in synthetic polymers using a specific molecule to guide the arrangement of the polymer structure. The process may be approached by designing the recognition site or by simply choosing monomers that may have favorable interactions with the imprinting molecule. The design option can be expected to form better binding sites. The process involves building a complex of an imprint molecule and associated polymerizable ligands. It requires selecting the optimal coordinating ligands for a specific molecule and synthesizing polymerizable analogs. The ligands are then used to form complexes with the specific molecule. The complex must be sufficiently sturdy to survive copolymerization. This is easier to obtain for metal ion imprinting due to ionic and coordinate covalent bonds. By copolymerizing the complexes with a matrix monomer and a suitable level of crosslinking monomer, the imprint complex becomes bound in a polymeric network. The network must be mechanically and chemically processed to liberate the imprinting species and create the binding site. 
Our work has centered around heavy metal and actinide ion complexation, specifically lead and uranyl ion. We have produced ion exchange resins and ion selective electrodes based on uranyl ion imprinting. We have characterized the materials and demonstrated their utility for analytical applications. These results are tabulated in the listed publications. We have extended the process to produce membranes that permit the selective migration of uranyl ion. $\mathrm{UO}_{2}{ }^{2+}$ was transported at higher rate with a selectivity factor $(\alpha)$ ranging from 114 to 152 . This selectivity is defined as the ratio of the molar concentration of uranyl ion to molar concentration of the competing metal ions measured in the receiving solution. This is the first solid polymer membrane that provides selective migration of metal ions from one solution to another solution that is not based on the size of the pores. The production of the membrane is a significant advance in the area of separation science. Such membranes have enormous potential for waste treatment and metal ion recovery and purification. Three graduate students received some support from this project resulting in two finished Master's Theses and one Ph. D. Dissertation near completion. 


\section{Research Objective}

The objective of this research was to develop polymeric extractants for the selective complexation of uranyl ions (and subsequently other actinyl and actinide ions) from aqueous solutions. Selectivity for a specific actinide ion is obtained by providing the polymers with cavities lined with complexing ligands so arranged as to match the charge, coordination number, coordination geometry, and size of the actinide ion. These cavity-containing polymers are produced by using a specific actinide ion (or surrogate) as a template around which monomeric complexing ligands are polymerized. The polymers provide useful sequestering agents for removing actinide ions from wastes and will form the basis for a variety of analytical techniques for actinide determination.

The project was aimed toward using an innovative technology to make a distinct improvement in metal ion sequestering analysis and recovery. The project was successful in all of its aims. The principle of ionic imprinting has been shown to make materials suitable for actinide removal, analysis and recovery. The materials developed by this research could be applied to the recovery of actinides from waste for their re-use and elimination from waste, thus reducing the waste disposal problem. The materials will function without the addition of organic solvents and their use will not generate mixed wastes. The production of a selectively ion permeable membrane was a significant fundamental advance in separation. science. A request for renewal described an approach to use the materials to cleanup solutions, but was not funded.

The facilities for the project were primarily located at the Johns Hopkins University Applied Physics Laboratory where the principle investigator is employed as a Senior Professional Chemist. Students were accessed through the Department of Chemistry and Biochemistry of the University of Maryland, Baltimore County, where the principle investigator has an appointment as Adjunct Associate Professor and was formerly an Associate Professor there.

\section{Methods and Results}

This report summarizes a three year period of performance. During this period the majority of the polymers tested were synthesized using three coordinating ligand monomers: vinyl benzoic acid, vinyl salicylaldehyde and vinyl salicylaldoxime. The structures of all of the coordinating monomers used to date are given in Figure 1. Uranyl compounds for each of these ligands were synthesized and the stoichiometry verified by elemental analysis. Copolymers were synthesized in sets of analogous composition to ascertain optimal uranyl binding ability. For example, nickel vinylbenzoate salt, uranyl vinylbenzoate salt and a vinylbenzoic acid blank were reacted with varying amounts of divinyl benzene (DVB), azobisisobutyronitrile (AIBN), pyridine (solvent), and styrene. The salt and blank concentrations remained constant at 5 weight percent while DVB concentrations varied by $2-4 \%$ of total reactant weight with AIBN remaining constantly at 1 weight $\%$. Polymerization was performed in scintillation vials by two different methods. Half of the reactions were performed at $60^{\circ} \mathrm{C}$ for 24 hours under an $\mathrm{N}_{2}$ atmosphere in a mineral oil bath, while the remaining half were performed under similar conditions except an ultrasonic bath was substituted for the mineral bath. The resulting polymers ranged from bubbly yellow-brown (uranyl salts) solids to bubbly dark green (nickel salts) solids. 
<smiles>C=CC(=O)O</smiles>
acrylic acid<smiles>C=CP(=O)(O)O</smiles>

methacrylic acid vinylphosphonic acid<smiles>C=Cc1ccc(C(=O)O)cc1</smiles><smiles>C=Cc1ccc(C(=O)OC)cc1</smiles><smiles>C=Cc1cc(C=C)cc(C(O)O)c1</smiles>

4-vinylbenzoic acid

4-vinylbenzoic acid, methyl ester

1,3-divinylbenzoic acid

$\mathrm{HO}$.<smiles>C=Cc1ccc(CN)c(O)c1</smiles>

4-vinylsalicylaldoxime<smiles>CCc1ccc(C(=O)CC(C)=O)cc1</smiles>

4-vinylbenzoylacetone<smiles>C=Cc1ccc(C(=O)CC(=O)c2ccccc2)cc1</smiles>

vinyldibenzoylmethane<smiles>C=C(C)C(=O)NC(=O)c1cccc(C(O)NC(=O)C(=C)C)n1</smiles>

\section{$\mathrm{N}, \mathrm{N}$-bis(methacryloyl)-pyridine-2,6-dicarboxamide}

Figure 1. Coordinating monomers for uranyl ion polymers.

The copolymers made with vinyl benzoic acid and vinyl salicylaldoxime have been examined using uranyl ion luminescence spectroscopy and compared to the luminescence spectra of the isolated analogous compounds. For example, the compounds of uranyl benzoate $\left(\mathrm{UO}_{2}\right.$ benzoate $\left._{2}\right)$, uranyl vinylbenzoate and the uranyl vinylbenzoate copolymer were investigated by low temperature $(77 \mathrm{~K})$ luminescence spectroscopy. The appearance of the spectra showed that the structural integrity of the complex is not compromised by the copolymerization process. The polymer prepared with N.N'-bis(methacryol)-pyridine-2,6dicarboxamide yielded the most intense luminescence.

Ion Exchange Resins. The resins were ground into a powder with a cryogenic ball mill and a fraction of uniform size was obtained using sieves. The ground resins are swollen, washed with acetone to remove unreacted monomer and eluted with acid to remove accessible metal ions. After drying, weighed quantities of resin are tested for their exchange capacity by batch loading and extraction. Uranyl ion and competing metal ions are measured using Inductively Coupled Plasma Mass Spectrometry (ICP-MS). The data suggest that for 5 weight percent benzoate 
complex, 4 weight percent crosslinking and sonication produces the highest capacity polymer. Sonication seems to have a greater positive effect on the polymers made with vinyl salicylaldoxime than those using vinyl benzoic acid. It has been observed that a sharp increase in selectivity occurs while the amount of crosslinking is being increased over a narrow range. This abruptness of the change in selectivity is much greater than the change observed in previous work on $\mathrm{Pb}^{2+}$ selective polymers. This may be due to the more complex geometry of uranyl ion.

A quantity of the above polymer composition has been applied to sequestration and preconcentration of uranyl from a complex matrix (seawater). The experiment was performed to see if the resin was capable of removing small amounts of uranium in a mixture of a wide variety of other metals ions, prior to determination by UV-VIS spectrophotometry.

Experiments were carried out to determine and compare percent recoveries of $\mathrm{UO}_{2}{ }^{2+}$ from tap water and seawater samples using Chelex-100 and the imprinted ion exchange resin. A systematic study was initiated to preconcentrate uranium ions using Chelex-100 and imprinted uranium resin followed by determination using ICP-AES and ICP-MS. A simplified extraction module was constructed using a method similar to that used with a lead imprinted resin. ICPAES was used to determine percent recoveries of uranium ion at various values of $\mathrm{pH}$.

The same loading conditions were applied to both the imprinted uranium resin and Chelex-100. For both resins, uranium was separated from the sample matrix and most of the co-existing ions and a 20-fold increase in concentration was obtained. Mass percent recovery of uranium in tap water and seawater samples at different $\mathrm{pH}$ values $(\mathrm{pH} 3.0-\mathrm{pH}$ 6.0) were compared for imprinted and Chelex-100 ion exchange resins. At $\mathrm{pH}$ below 3.0 both resins can be expected to recover the same amount of uranyl ion since the acid functionalities are protonated and uranyl is increasingly stable with lowered $\mathrm{pH}$. Of main interest is the ability to extract uranium at elevated $\mathrm{pH}$ since binding of uranyl must be strong enough to shift the equilibrium of hydrolysis to form uranyl ion. All the recovery data was obtained using ICPAES. The data demonstrate that the uranyl ion imprinted resin is suitable for quantitative preconcentration of uranyl ion from a complex matrix, such as seawater.

Optimal $\mathrm{pH}$ and flow rate values were established, resulting in a $101 \pm 1$ percent recovery of uranyl ion using the imprinted uranyl resin. The optimal $\mathrm{pH}$ for the extraction of uranyl ion was found to be 3.0 and the flow rate was set at $4 \mathrm{~mL} \mathrm{~min}^{-1}$. The highest percent recovery resulted from Chelex-100, which was $103 \pm 1$ percent using the same flow rate. Values in excess of 100 percent indicate additive interferences. The ammonium form of Chelex-100 and the uranium imprinted resins were gradually neutralized by the bicarbonate and the hard metal ions present in seawater so that a plot of $\mathrm{pH}$ versus percent recovery resembles that of a typical acid-base titration curve. The recovery data for the imprinted polymer extraction of $\mathrm{UO}_{2}{ }^{2+}$ from tap water compared to the data for seawater suggested that the ammonium form of the resin was less useful for extraction from solution than an alkali metal form. Thus, the Chelex-100 and uranyl imprinted ion exchange resins were converted to $\mathrm{Na}^{+}$ form by passing $4.0 \mathrm{M} \mathrm{NaCl}$ solution through each ion exchange column. After $250 \mathrm{~mL}$ of spiked uranium tap water solution was preconcentrated by factor of 10 , the percent recovery of uranyl ion was analyzed by ICP-MS. Once the resin was converted to $\mathrm{Na}^{+}$form, the percent recovery of $\mathrm{UO}_{2}{ }^{2+}$ increased by an additional 10 and 12 percent at $\mathrm{pH} 3.5$ using Chelex-100 and the uranyl imprinted ion exchange resin, respectively. 
Colorimetric Analysis. Extraction of uranium ions followed by colorimetric detection is a simple and convenient method for the determination of uranium in water samples. Eluted uranium was determined by a photometric method using dibenzoylmethane complexation with uranyl ions (Table 1). A $250 \mathrm{~mL}$ solution of 100 parts per billion (ppb) uranyl ion in deionized water $(\mathrm{pH}=3.5)$ was passed through the uranyl imprinted resin, then extracted into a $25 \mathrm{~mL}$ volumetric flask. The $\mathrm{pH}$ of this solution was adjusted with addition of $1.0 \mathrm{M} \mathrm{HNO}_{3}$ solution until the $\mathrm{pH}$ 3.5. This extraction procedure resulted in a preconcentration factor of 10 . The recovery of the uranyl ion determined using dibenzoylmethane was in agreement with the ICPMS result. This experiment was performed in order to verify that the photometric method of analysis worked adequately with the resin extracts. This procedure was then applied to extracted seawater and a NIST glass samples.

Quantitation of recovery of $\mathrm{UO}_{2}{ }^{2+}$ using dibenzoylmethane with the eluents from Chelex-100 and uranyl imprinted resins was performed. The quantitative yields of the uranyl ions by imprinted resins, determined photometrically agreed with the results obtained by ICPAES. However, the concentration of the uranyl ions extracted by Chelex-100 ion exchange resin could not be determined photometrically. Once the

Table 1. Determination of $\mathrm{UO}_{2}{ }^{2+}$ in the spiked D. I. water using the uranium imprinted ion exchange resin $(\mathrm{N}=3, \pm \mathrm{RSD}){ }^{\mathrm{a}}$

\begin{tabular}{cccc}
\hline Method of Analysis & $\begin{array}{c}\text { Experimental } \\
\text { Concentration of } \\
\mathrm{UO}_{2}^{2+}, \mathrm{ppm}\end{array}$ & $\begin{array}{c}\text { Expected } \\
\text { Concentration of } \\
\mathrm{UO}_{2}^{2+}, \mathrm{ppm}\end{array}$ & $\%$ Recovery \\
\hline Photometry & $1.03 \pm 0.10$ & $1.00 \pm 0.01$ & 100.3 \\
ICP-MS & $1.08 \pm 0.94$ & $1.00 \pm 0.01$ & 100.8 \\
\hline
\end{tabular}

a The analyses reflect 10 fold preconcentration.

uranium-dibenzoylmethane complex was formed from the Chelex-100 seawater extract a colloidal precipitate appeared, clouding the solution, thereby preventing photometric analysis. To verify the accuracy of the photometric method, a reference material was sought that would produce a very complex matrix. The NIST standard reference material, SRM 610 Trace Elements in Glass was selected for analysis. The glass samples were ground to a fine powder and dissolved by microwave digestion. A portion of the digest, diluted to reduce acidity to a $\mathrm{pH}$ of 3.0, was passed through the imprinted resin and concentrated by a factor of 10 . ICPMS and UV/VIS spectrometry methods were used to determine the concentration of $\mathrm{UO}_{2}{ }^{2+}$. The limit of detection (LOD) for the dibenzoylmethane method was established as $160 \mathrm{ppt}$. Results obtained from the spectrophotometric analysis and the analysis by ICP-MS were in good agreement with the certified value (Table 2).

Table 2. Determination of Uranium in the unspiked NIST 610 Trace Elements in Glass sample using uranium imprinted ion exchange resin. 


\begin{tabular}{cccc}
\hline $\begin{array}{c}\text { Ion Exchange Resin } \\
\text { Used }\end{array}$ & Analytical Method & $\begin{array}{c}\text { Experimental } \\
\text { Concentration of } \\
\mathrm{UO}_{2}^{2+}, \mathrm{ppm}^{\mathrm{a}}\end{array}$ & $\begin{array}{c}\text { Certified } \\
\text { Concentration of } \\
\mathrm{UO}_{2}^{2+}, \mathrm{ppm}^{\mathrm{a}}\end{array}$ \\
\hline $\begin{array}{c}\text { Uranyl Imprinted } \\
\text { Resin }\end{array}$ & $\begin{array}{c}\text { Photometry } \\
\text { (Dibenzoyl- } \\
\text { methane) }\end{array}$ & $463.6 \pm 3.7$ & $461.5 \pm 1.1$ \\
ICP-MS & $460.5 \pm 2.5$ & $461.5 \pm 1.1$ \\
Chelex-100 & $\begin{array}{c} \\
\end{array}$ & & \\
& Photometry & & \\
& (Dibenzoyl- & & \\
& methane) & $501.70 \pm 5.7$ & $461.5 \pm 1.1$ \\
\hline
\end{tabular}

a Relative standard deviation for $\mathrm{n}=5$ determinations.

Although within the margin of error, the uranium content of the standard glass determined using dibenzoylmethane with the Chelex-100 eluent was in slight excess of 100 percent, likely due to additive interferences from other soft metal ions in the extract. The results obtained from ICP-MS analysis for the Chelex-100 eluent also gave a higher value than expected. This phenomenon has been explained in terms of the solvent composition effect in ICP-MS, where small changes in acid concentration can be important when the acid concentration is low. Changing the concentration of strong acids such as $\mathrm{HCl}, \mathrm{HNO}_{3}$, or $\mathrm{HF}$ from $10^{-4}$ or less to $10^{-3}$ percent v/v can result in up to a 20 percent increase in ICP-MS signal due to solvent viscosity change, reduced nebulizer uptake rate, etc.

The quantitative data obtained from the imprinted resin determined using the dibenzoylmethane complex agreed with the earlier experiment using ICP-AES. Both results were within acceptable margins of error. The photometric results allowed the determination of uranium ions with less extensive separation, a simpler apparatus, and more accuracy than ICPMS. These results suggest that the combination of the imprinted ion exchange resin and dibenzoylmethane colorimetric method could provide a simple and inexpensive analytical method for the determination of uranyl ion in aqueous solutions, even in the case of complex matrices such as seawater.

Ion Selective Electrodes. Several polymer formulations have been incorporated into membranes and tested as ion selective electrodes. The formula used to make uranyl ion selective electrodes has been modified to extend the operational lifetime from weeks to months. The variables in the optimization of the electrode performance include: 1) adjusting polymer formulations, 2) varying the plasticizers and their relative amounts in the formulations, and 3) changing membrane compositions. The copolymers made with vinyl salicylaldoxime exhibit better selectivity than those prepared with vinyl benzoic acid. The calibration plots show that the response of the vinyl salicylaldoxime membranes to high levels of interfering ions is less than the response to uranyl ion at the detection limit (Figure 2.). Attempts to make a composite membrane for the electrode has met limited success. The response of the composite membrane 
gave a lesser calibration slope and was erratic. The problems with the composite membrane stem from too great a thickness for conductivity. This is a fabrication issue that we will address in the near future.

The electrode membranes were prepared by mixing $90 \mathrm{mg}$ of PVC powder and $30 \mathrm{mg}$ of $\mathrm{UO}_{2}{ }^{2+}$ templated polymer particles with $0.2 \mathrm{~mL}$ of plasticizer (DOPP). Stirring until the PVC was well moistened, the mixture was dissolved in $3.0 \mathrm{~mL}$ of THF and stirred for another $20 \mathrm{~min}$ with a magnetic stirrer. The resulting mixture was poured into a glass ring with an internal diameter of $45 \mathrm{~mm}$ on a glass plate, and THF was allowed to evaporate at room temperature for 2 days. The membrane was attached to a PVC tube with diameter of $6.5 \mathrm{~mm}$ using a viscous solution of PVC in THF as adhesive. The tube-bound section was then cut from the rest of the membrane material with a razor blade. The resulting electrode was filled with $1 \mathrm{mM}$ $\mathrm{UO}_{2}\left(\mathrm{NO}_{3}\right)_{2}$ and $1 \mathrm{mM} \mathrm{NaCl}$ internal solution and conditioned for $24 \mathrm{~h}$ by soaking in a $1 \mathrm{mM}$ of $\mathrm{UO}_{2}\left(\mathrm{NO}_{3}\right)_{2}$ solution. The internal electrode consists of an $8.0 \mathrm{~cm}$ long $0.25 \mathrm{~mm}$ diameter $\mathrm{Ag}$ wire (Aldrich) coated with $\mathrm{AgCl}$ on $2.0 \mathrm{~cm}$ of the distal end.

All measurements were made with a model 350 Corning $\mathrm{pH} /$ ion Analyzer. The ISE additionally required the use of a high flow $\mathrm{Ag} / \mathrm{AgCl}$ reference electrode, manufactured by Orion. The cell schematic is thus: $\mathrm{Ag} \mid \mathrm{AgCl}, \mathrm{KCl}$ (sat. $)||$ test soln |PVC membrane $\left|\left(1 \mathrm{mM} \mathrm{UO}_{2}\left(\mathrm{NO}_{3}\right)_{2}, 1 \mathrm{mM} \mathrm{NaCl}\right)\right| \mathrm{AgCl} \mid \mathrm{Ag}$

The performance of the electrode was investigated by measuring the e.m.f. values of the various metal ion solutions. The activities of the metal ions were based on the activity coefficient $(\gamma)$ calculated from the modified form of the Debye-Hückel equation:

$$
\log \gamma_{ \pm}=-0.511 \times Z^{2} \times\left(\frac{\sqrt{I}}{1+1.5 \times \sqrt{I}}-0.2 \times I\right)
$$

where $\mathrm{I}$ is the ionic strength, and $\mathrm{Z}$ is the valence of the metal ion.

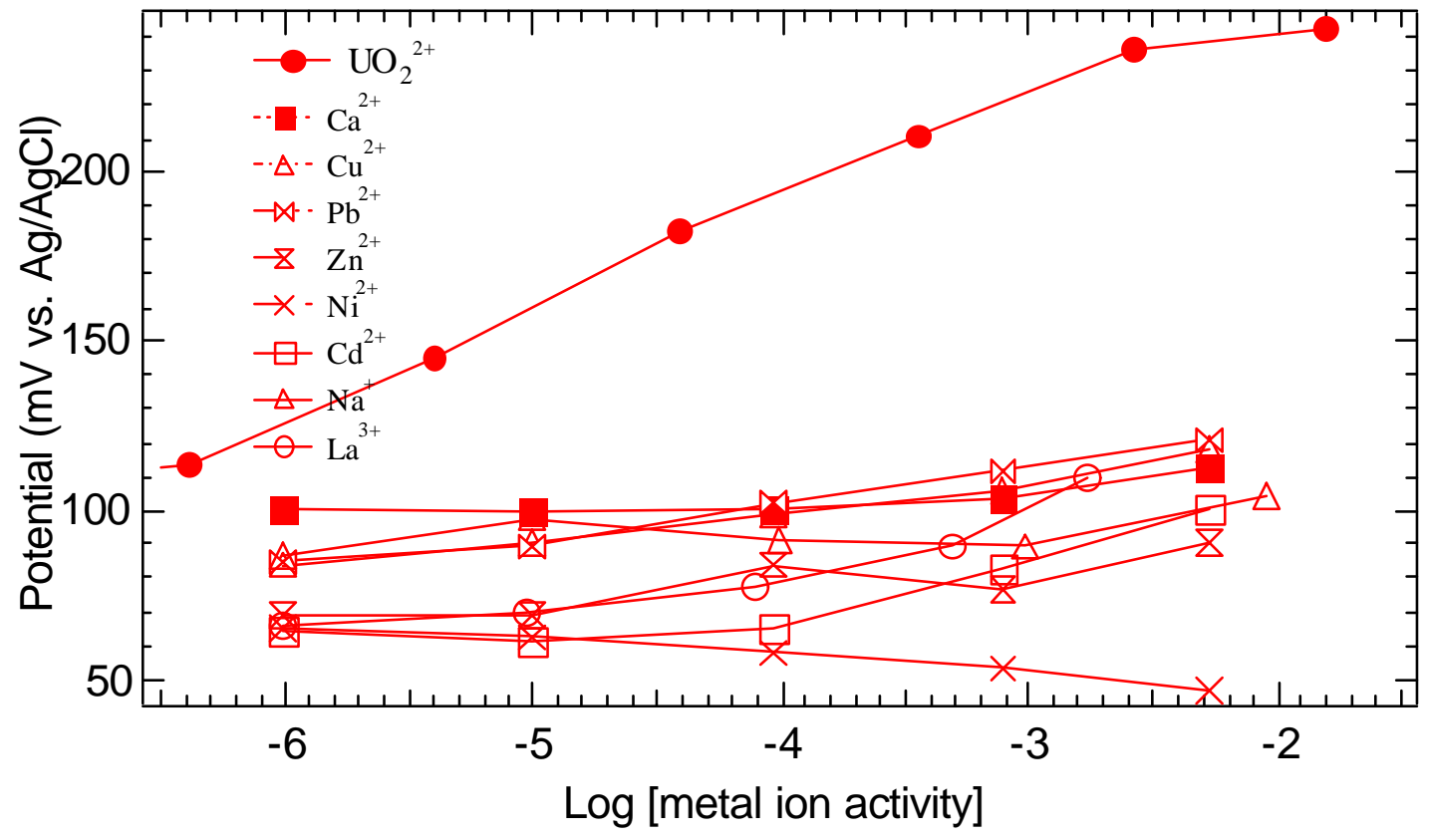


Figure 2. Response of ion selective electrode prepared from imprinted salicylaldoxime showing insensitivity to common interferents.

Selectively Permeable Membrane. The molecular imprinting process has been applied to the production of membranes for the selective permeation of uranyl ion. While working on a composite ion selective electrode membrane, it was determined that a robust membrane could be fabricated but the thickness precluded its use in an electrode. The membranes swelled in aqueous solution and seemed to have a good loading capacity. The commonly used porogens were rejected as being too small to form channels to span the membrane. Thus a linear polymeric porogen was used that was removed during the final phase of membrane preparation. This polymer has polar functional groups that may be interacting with the polymerizable metal ion complexes to impart regularity to their dispersion in the film. The resultant polymer membranes appear to allow selective permeation of uranyl ion in the presence of several interferences. These findings will require further experiments to verify the preliminary results and to determine the selectivity and kinetics of membrane transfer.

A scanning electron micrograph of the membrane shows that the surface of the membrane has pores in the micron and submicron range (Figure 3). The pores allow access to the membrane channels. Energy dispersive X-ray emission spectra of the pore area show larger amounts of uranium in the pores relative to the surrounding area (Figure 4). The result further suggests that the pores are involved in metal ion transport. Preliminary data obtained for the membrane are given in Tables 3 and 4.

Permeable membranes were prepared using uranyl vinylbenzoate, $\mathrm{UO}_{2}(\mathrm{VBA})_{2}$ as the ion imprinting complex. Styrene was used as the matrix monomer and divinylbenzene was used as the cross linking monomer. Membrane synthesis was carried out in a screw-top vial by dissolving the uranyl vinylbenzoate complex (20 to $150 \mathrm{mg}$ ), in a solution consisting of $400 \mathrm{~L}$ of nitrophenyl octyl ether (NPOE) as a plasticizer. $22 \mathrm{mg}$ of a polyester, prepared from diglycolic acid and 1,6 hexanediol, was added in the polymerisation mixture. After deaeration of the mixture with dry nitrogen, $20 \mathrm{mg}$ of a free radical initiator, 2,2'-azobisisobutyronitrile $(\mathrm{AIBN})$ was added. The vial was sealed and placed in a sonicator at $60^{\circ} \mathrm{C}$. The solution was sonicated until viscous, and the viscous solution was poured into a Teflon mold. The resultant mold was kept in a sealed container and placed in an oven at $60^{\circ} \mathrm{C}$ for 18 hours to complete the polymerisation. A reference membrane that did not contain the uranyl ion as the template was prepared in the same manner. The reference membrane was imprinted with nickel. The uranyl template and the polyester were removed using a $0.1 \mathrm{M}$ acetic acid solution followed by a $5 \%$ nitric acid solution. Uranyl ions were removed using excess of the acid until the entire template was recovered. The membrane was then washed with deionised water until the acid was removed. The reference membrane was treated in the same way. The thickness of the resulting membranes was approximately $100 \mathrm{~m}$. Transport studies were carried out in a Ushaped tube consisting of two detachable parts. The membrane, with an exposed crosssectional area of $0.613 \mathrm{~cm}^{2}$, was placed between the two halves of the tube. The two halves were held together with a screw-actuated clamp that compresses an o-ring seal to tightly secure the connection. Experiments were performed under quiescent condition and also by stirring the solutions. The time-dependence of uranyl ion transport in quiescent solution is given in Figure 5. 


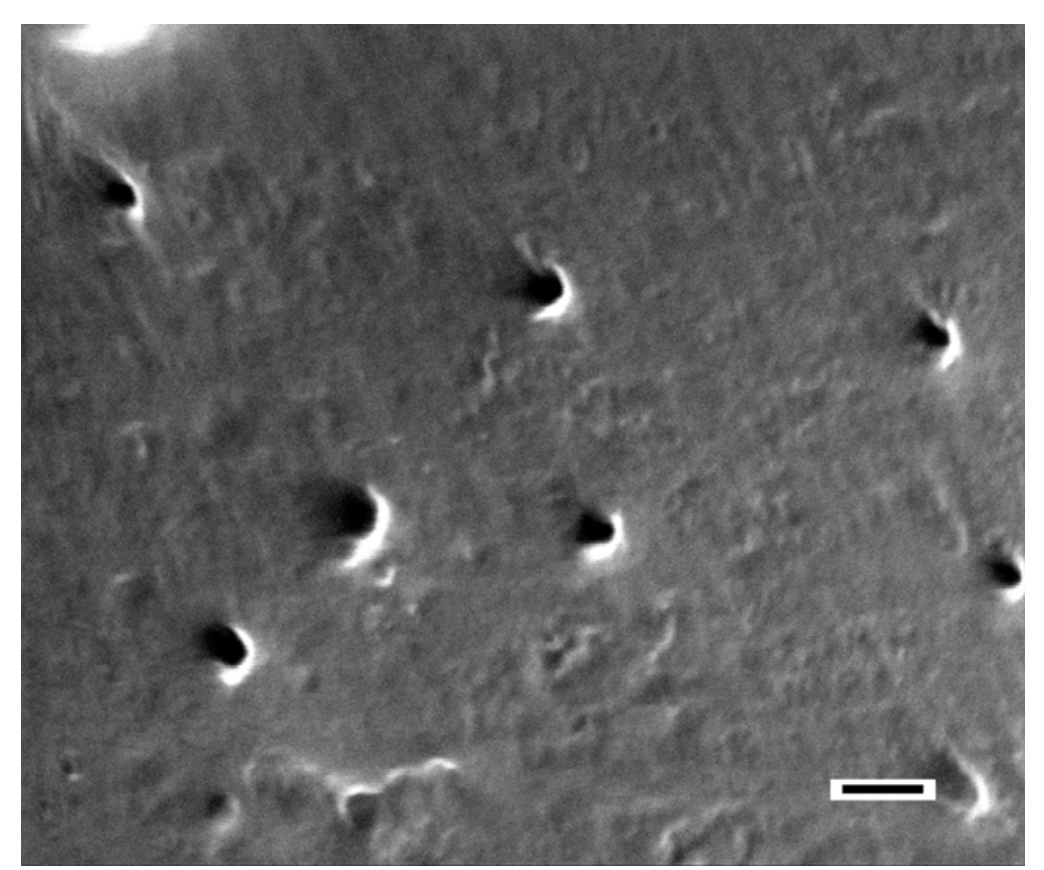

Figure 3. Scanning electron micrograph of the membrane surface showing submicron pores (the mark at the lower right is one micron).

Table 3: Uranyl ion permeation through the membrane

$\begin{array}{llll}\begin{array}{l}\text { Feed Solution } \\ (\mathrm{ppm})\end{array} & \begin{array}{l}\text { Membrane thickness } \\ (\mu \mathrm{m})\end{array} & \begin{array}{l}\text { Time } \\ (\mathrm{Hrs})\end{array} & \begin{array}{l}\text { Conc. of U } \\ (\mathrm{ppm})\end{array} \\ 100 & 381 & 24 & 3.34 \pm 0.07 \\ 100 & 127 & 24 & 5.85 \pm 0.10\end{array}$

Table 4: Uranyl ion permeation in the presence of competing metal ions

$\begin{array}{llll}\begin{array}{l}\text { Feed Solution } \\ (\mathrm{ppm})\end{array} & \begin{array}{l}\text { Permeation Time } \\ (\mathrm{Hrs})\end{array} & \text { Metal Ion } & \begin{array}{l}\text { Conc. } \\ (\mathrm{ppm})\end{array} \\ 47.6 & 45 & \mathrm{UO}_{2}{ }^{2+} & 1.31 \pm 0.04 \\ 47.6 & 45 & \mathrm{Ni}^{2+} & 0.01 \\ 47.6 & 45 & \mathrm{Cd}^{2+} & 0.02\end{array}$




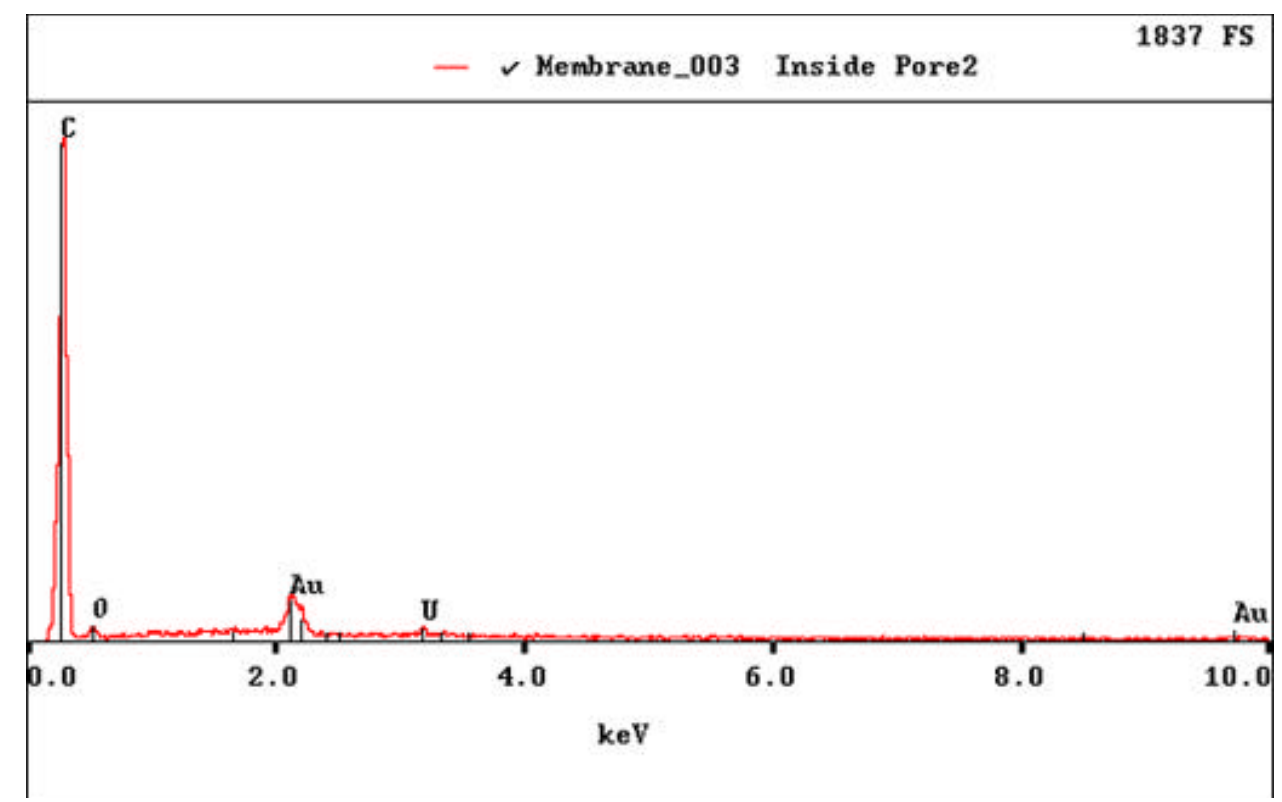

Figure 4. Energy dispersive X-ray fluorescence of the inside of a membrane pore showing presence of uranium.

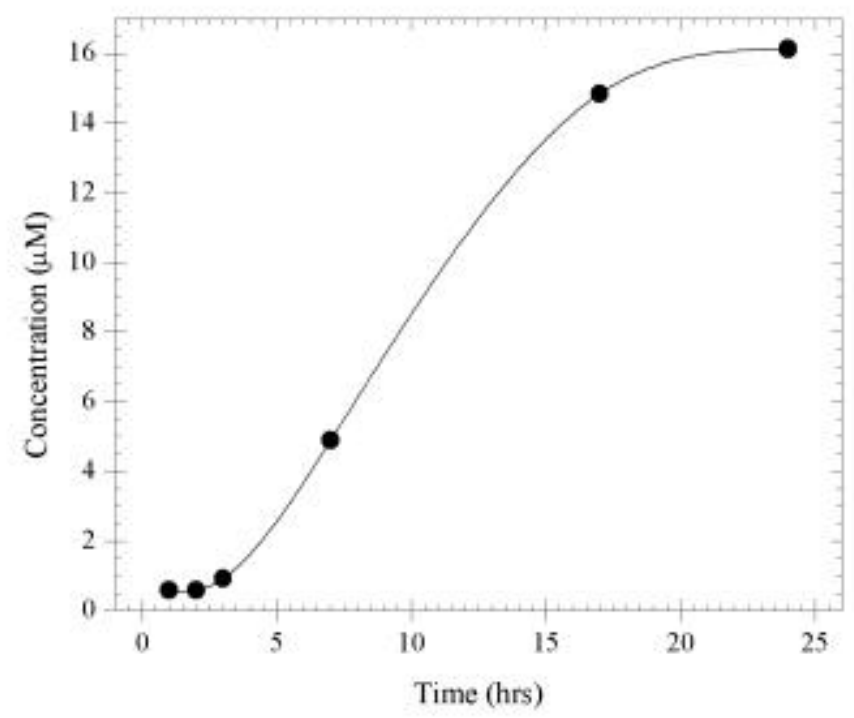

Figure 5. Uranyl ion permeation as a function of time.

Uranyl Optical Sensor. Ionic templating was also an approach of choice in preparing a luminescent sensor for determination of uranyl in aqueous solutions. It was reconfirmed that 2,6-pyridinedicarboxylic acid (DPA) forms complexes with uranyl that are strongly luminescent. The luminescence of these complexes is significantly stronger than that of the ones formed with alternative ligands, such as benzoate and salicylaldoxime, and therefore provides for a better luminescence-based sensor. A chemical modification of the ligand is necessary, however, to provide it with polymerizability. Thus, a diamide derivative of DPA was synthesized, using 2,6pyridinedicarbonyl dichloride and methacrylamide, which preserves the essential configuration of the chelating moiety and adds two vinyl-terminated polymerizable side chains. The uranyl 
complex with the modified ligand exhibited luminescent properties similar to those of DPA uranyl chelates. Unfortunately, low solubility of the complex in the regularly employed matrix monomers limits its usefulness in the styrene-based polymer systems, and currently new host polymers are being investigated along with other means of enhancing the solubility of the polymerizable complex.

\section{Relevance, Impact, and Technology Transfer}

a. How does this new scientific knowledge focus on critical DOE environmental management problems?

This technology enables DOE environmental management to shift their clean-up strategy from one of waste disposal to one of resource recovery. It would save DOE resources by preconcentrating the undesirable contaminants and drastically reducing the volume of waste to be disposed. The current approach to dealing with the problem of inherited environmental problems is to generate large quantities of waste materials. This leads to high cost in packaging the waste materials in some perceived safe form with the hope that the storage location of such materials will be safe for hundreds of years. An alternative strategy is to use innovative technologies to find ways to recover the valuable components of the waste for re-use and thus reduce the amounts for waste disposal and storage elsewhere This requires methods of separation that are re-usable and don't employ organic solvents. While the EMSP desires innovative technologies, "safe" management funding appears to go to incremental projects of known disadvantages. Our technology promises to be a quantum advancement for managing DOE's environmental management problems. However, it requires funding to go into Phase 2, the manufacturing development phase. We have not been selected for Phase 2.

b. How will the new scientific knowledge that is generated by this project improve technologies and cleanup approaches to significantly reduce future costs, schedules, and risks and meet DOE compliance requirements?

While the scientific gains from the project are considerable, it is unlikely that the technology will have a short term impact since it has just started and is not being continued. Selective sequestration of environmental hazards would significantly reduce costs, schedules and risks to DOE's compliance requirements. We have reported that this is possible using molecularlyimprinted polymeric filters and sensors.

c. To what extent does the new scientific knowledge bridge the gap between broad fundamental research that has wide-ranging applications and the timeliness to meet needs-driven applied technology development?

Additional funding to manufacture and field test the present molecularly-imprinted polymers would bridge the gap from the laboratory and into field use. 
d. What is the project's impact on individuals, laboratories, departments, and institutions? Will results be used? If so, how will they be used, by whom, and when?

We intend to use these results to continue to develop other selectively permeable membranes. These membranes will have application to industry and medicine. We have already used our materials to do chemical analysis and uranium recovery from seawater. We intend to continue our environmental focus, albeit at a slower pace, and hopefully attract funding from other government agencies and/or a commercial venture capitalist.

e. Are larger scale trials warranted? What difference has the project made? Now that the project is complete, what new capacity, equipment, or expertise has been developed?

We have gained expertise in making highly selective actinide ion membranes. This technology needs to be transitioned into a larger prototyping manufacturing facility and to conduct "drum" scale field testing.

f. How have the scientific capabilities of collaborating scientists been improved?

Several students have received or will soon receive advanced degrees. All of our expertise in molecular imprinting has been advanced.

g. How has this research advanced our understanding in the area?

This research has resulted in a fundamental advancement in separation science. Selectively permeable membranes can form the basis of efficient methods for resource acquisition or recovery.

h. What additional scientific or other hurdles must be overcome before the results of this project can be successfully applied to DOE Environmental Management problems?

The fundamental knowledge gained by this work needs to be refined into a manufacturability product and then field tested at a DOE facility.

i. Have any other government agencies or private enterprises expressed interest in the project? Please provide contact information.

No, we have not contacted any other government agency.

\section{Project Productivity:}

The project exceeded its objectives and formed the basis for an application for renewal for demonstration project. This application was rejected and therefore will be redirected into other metal ions of interest to other potential sponsors.

\section{Personnel Supported}


Principal Investigator: Dr. George M. Murray

Co-investigator: Dr. O Manuel Uy

Co-advisor for Anael Kimaro: Dr. Lisa A. Kelly

Graduate Students: Dr. Xiangfei Zeng, Sue Y. Bae, Anton Bzhelyanskiy \& Anael Kimaro

VII. Publications

1. Zeng, X. Bzhelyansky, A., Bae, S. Y., Jenkins, A. L. and Murray, G. M. "Templated Polymers for the Selective Sequestering and Sensing of Metal Ions," in, Molecular and Ionic Recognition with Imprinted Polymers, ACS Symposium Series 703, Bartsch, R. A. and Maeda, M., Eds., American Chemical Society, Washington, D. C., 1998.

2. Murray, G. M., Jenkins, A. L., Bzhelyansky, A. and Uy, O. M., "Molecularly Imprinted Polymers for the Selective Sequestering and Sensing of Ions," JHUAPL Technical Digest, 18, 432-441 (1997).

3. Bae, S. Y., Southard, G. L. and Murray, G. M., "Molecularly Imprinted Ion Exchange Resin for Purification, Preconcentration and Determination of $\mathrm{UO}_{2}{ }^{2+}$ by Spectrophotometry and Plasma Spectrometry," Analytica Chimica Acta, 397, 173-181 (1999).

4. Arnold, B. R., Jenkins, A. L., Uy, O. M. and Murray, G. M., "Progress in the Development of Molecularly Imprinted Polymer Sensors," JHUAPL Technical Digest, 20, 190-198 (1999).

5. Kimaro, A. and Murray, G. M., "Synthesis and Characterization of Templated Ion Exchange Resins for the Selective Complexation of Actinide Ions," Abstract No. 2315P, Pittsburgh Conference, March 7-12, 1998, Orlando, Florida.

6. Bae, S. Y., "Extraction and Preconcentration of Ultratrace Lead and Uranium ions in Seawater and their Determination by Photometric and Plasma Spectrometry," Master's Thesis, University of Maryland, Baltimore County, 1998.

7. Bzhelyanskiy, A., "Uranyl Imprinted Polymers in Chemical Sensing," Master's Thesis, University of Maryland, Baltimore County, 2000.

8. Murray, G. M. and Uy, O. M., "Ionic Sensors Based on Molecularly Imprinted Polymers," in Molecularly Imprinted Polymers, Sellergren, B., Ed., Elsevier, Amsterdam, 2001.

9. Kimaro, A., Kelly, L. A. and Murray, G. M., "Uranyl Ion Imprinted Polymer for Sensor Application," The Manhattan Poster Project VI, November 16-17, 1998, NIST, Gaithersburg, Maryland.

10. Kimaro, A., Kelly, L. A. and Murray, G. M., "Uranyl Ion Imprinted Polymer. Synthesis, Characterization and Application. Graduate Student Research Day, April 21, 1999, University of Maryland Baltimore, Baltimore, Maryland. 
11. Kimaro, A., Kelly, L. A. and Murray, G. M., "Imprinted Permeable Membrane for Uranyl Ion," 220th ACS National Meeting, August 20-24, 2000, Washington, D.C.

12. Zeng, X., "Metal Ion Selective Sensors Based on Molecularly Imprinted Polymers," Dissertation, University of Maryland, Baltimore County, 2000.

VII. Interactions

a. Participation/presentations at meetings, workshops, conferences, seminars, etc.

This information is, for the most part, described under publications but included the DOE EMSP sponsored workshops held during the project.

b. Consultative and advisory functions to other laboratories and agencies, especially DOE and other government laboratories.

The Johns Hopkins University Applied Physics Laboratory acts as a trusted agent for a large number of governmental agencies and as a staff member, the principle investigator provides a variety of consultation services to a large number of agencies on a daily basis.

c. Collaborations

For this project, collaboration was maintained with Dr. Richard Haire of the Tansuranium Research laboratory located at the Oak Ridge National Laboratory.

VIII. Transitions

a. Describe cases where knowledge resulting from your effort is used, or will be used, in a technology, technique, or process improvement application. Transitions can be to entities in DOE, other federal agencies, or industry.

We intend to develop this technology for the separations of important minerals from mining leachate solutions. We also intend to pursue the application of this technology for medical purposes. Since we were unsuccessful at obtaining continued support from the EMSP, we intend to seek sponsorship from other sources.

b. Briefly list the enabling research, the laboratory or company, and an individual in that organization who made use of your research.

None.

IX. Patents

A provisional patent application has been filed. 


\section{Future Work:}

Previous approaches to making molecularly imprinted ion exchange resins for metal ions have produced resins that exhibit varying but usually only slightly improved amounts of selectivity. These materials were produced by following the conventional wisdom of using large amounts of covalent crosslinking. We have found that higher selectivity can be obtained by using much less covalent crosslinking. We have further discovered that an optimal amount of covalent crosslinking can be achieved, based on elucidation of the relevant complexation constant as measured by batch extraction studies. These observations may be a result of a methodology that employs little or no porogen and intentionally leaves residual metal ion crosslinks. We would like to investigate the effects of low level metal ion crosslinking on molecularly imprinted ion exchange resins.

The greatest general utility of the use of metal ions to form imprinted polymers may be the change afforded in structural properties. The inclusion of cations into polymer acids to form polymer salts drastically changes the relaxation and other physical properties due to strong coulombic interchain interactions. The effect is to raise the glass transition temperature and impede post fabrication structural relaxation. When trying to produce a stable rebinding site in an imprinted polymer it is important to maintain site integrity. Ionic crosslinks through metal ions should help maintain site integrity. Since metal ion crosslinking has a greater effect on polymer properties than does covalent crosslinking, less total crosslinking can be used and some of the ligand recoil effected by imprint ion removal may be mitigated. This expectation is one of the key concepts that needs to be examined by this work.

If we are able to find sponsorship, we would perform the following work. The uranyl ion sequestering agent should be optimized and tested against a broader range of interferences. Levels of crosslinking should be carefully evaluated in order to better understand the abrupt changes in selectivity. The ion selective electrode work will continue with the goal of fabricating membranes without using a PVC matrix. Plasticizer and ionophore will be added directly to the mixture of metal-ligand complex and spin-coated after the polymerization has been initiated in order to achieve appropriate thickness. The selective ion permeating membrane will also be fabricated by the spin coating method to effect a higher uranyl throughput. The luminescent uranyl compounds will be used to construct optical sensors.

\section{Literature Cited}

The literature cited appears under the above heading of publications.

\section{Feedback}

There are several aspects to EMSP sponsorship that cause concern. The first problem encountered was the expected attendance of workshops. If it is to be expected that the researchers come to these workshops, they should be warned and advised to include them in their budgets. The second issue is reporting. Each year a different procedure is presented to 
file reports. Invariably, someone one is left out of the instructions and later demands their copy of the report, declaring it overdue. It would seem logical to come to some consensus about reports and be consistent. Third, there needs to be some consistency about innovation. If innovation is desired, then fund innovation. Finally, it appears that EMSP has become a mechanism that is primarily designed to sponsor DOE laboratories. If the required expertise were available in-house, there wouldn't need to be an EMSP.

XIII. Appendices

None. 